\title{
Study on IBS Cooling Panel Wall System with Difference Types of Cooling Mediums
}

\section{Eny Nor Syahira Mohamad Hashim ${ }^{1}$, Norhafizah Salleh ${ }^{2 *}$, Noor Azlina Abdul Hamid $^{2}$}

${ }^{1}$ Department of Building and Construction Engineering, Faculty Of Civil And Environmental Engineering, Universiti Tun Hussein Onn Malaysia (UTHM), 86400 Parit Raja, Batu Pahat, Johor, MALAYSIA

${ }^{2}$ Department of Structural and Material Engineering, Faculty Of Civil And Environmental Engineering, Universiti Tun Hussein Onn Malaysia (UTHM), 86400 Parit Raja, Batu Pahat, Johor, MALAYSIA

*corresponding author

DOI: https://doi.org/10.30880/ijscet.2020.11.02.011

Received 30 July 2020; Accepted 30 August 2020; Available online 02 September 2020

\begin{abstract}
This paper proposes a cooling house system that can promote thermal comfort in buildings without airconditioning. The cooling panel wall forms a part of an Integrated Building System (IBS), and is essentially made of tubes filled with either water or glycerin as the coolant. Target strength for the panel wall was designed based on the Malaysian Standard (MS) while the building ventilation system followed the American Society of Heating, Refrigerating, and Air Conditioning Engineers (ASHRAE) standard. The results are reported based on indoor and outdoor temperature difference together with relative humidity to identify the best performing house model and also coolant. The outcome of this research is expected to add value to design concepts with a better promotion of air flow and circulation in the building, without over-usage of natural resources and higher building cost to achieve the same objective.
\end{abstract}

Keywords: cooling panel, glycerin medium, water medium

\section{Introduction}

A cooling house system describes the ventilation in an enclosed area that brings thermal comfort to the occupants. Such system is widely used in heritage house design (Ibrahim et al.,2015), which generally promotes better ventilation compared to modern house design even though it may translate into higher natural resources usage and building cost. Thermal comfort is achieved when there is a good flow of air circulated from the outside into the building. It is the main factor for the productivity and health of the occupants in the residential building (Parakash et.al ., 2015). However, since the past 100 years, global average surface temperature had increased about $0.74 \mathrm{oC}$ and led to extreme environmental condition such as the infamous El Nino (Malaysia M.D, 2009). This means that achieving thermal comfort has become more challenging since our air has become hotter than it used to be a century ago. As such, a cooling house system has to be in place to enhance thermal comfort.

This research proposes a cooling house system which forms a part of an Integrated Building System (IBS) panel wall to enhance thermal comfort in a building. This is in view that IBS is a popular building solution in Malaysia to shorten project schedule and labour cost. In addition, it is more environmental-friendly since the walls are pre-fabricated in factories to reduce material wastage at site. The proposed cooling system in this research embeds the favourable properties of coolants such as air, water and glycerin into the wall ventilation system (Myhren et.al., 2008). This wall 
allows the flow of outdoor air surrounding the house and under roof space for internal ventilation. Undoubtedly, some modification to a common IBS wall panel is required to allow the air transfer and the material should also be ideal for heat absorption. An example is the foamed concrete commonly used in western countries that has low conductivity and provides better thermal insulation properties (Mohamad, 2010). This research has also adopted foam as the main concrete binder to produce the Precast Lightweight Foam Concrete Panel (PLFP).

The cooling house system IBS panel wall in this research has built-in coolant tubes, tested with either water or glycerin as the coolant of choice. Thermal experiments were conducted to compare the indoor and outdoor temperatures for two house models. The first model was a brick house with no cooling system, which resembled the common houses in Malaysia. The second brick house model was embedded with IBS panel walls which contained the proposed cooling house system. Experiments were further conducted to identify the thermal performances of both water and glycerin as the coolant. The use of bricks may improve ventilation system, but since current construction trend favours IBS system, modification of a common IBS panel wall to improve ventilation seems like a wiser decision.

\subsection{Material and Research Method}

Two brick house models were built during this research. The first was an ordinary brick house and the second was had IBS panel wall embedded with the cooling house system. The wall panel with cooling system is termed the "Precast Lightweight Foam Concrete Panel" (PLFP). The thickness of PLFP was determined based on standard brick thickness of 90 to $100 \mathrm{~mm}$.

The cooling system was made of cooling tubes, with sizes determined based on published studies and shall be discussed in detail after this. Prototypes of the cooling system with either water or fine glycerine as coolant were constructed and embedded into the PLFP. Effectiveness of the cooling system was determined based on thermal and humidity testing. The test period was two weeks, with records taken four times daily at 7:00a.m., 12:00p.m., 4:00p.m., and 7:00p.m.

\subsection{Coolant Material}

Glycerin has many applications and it is abundantly available in the form of triglycerides - a combination of glycerin and fatty acids present in almost all vegetables, animal fats and oil (Miner et.al., 2010). Glycerin has been commercially used in United State in the form of glycerol, although it is frequently called as glycerin as well. Glycerin is found in urethane foams, alkyds resin, drugs, foods, tobacco, dentifrices and cosmetics. According to Mbamalu, V. C.(2013), the chemicals properties of glycerin such as viscosity, high boiling point, hygroscopic nature and non-toxicity are the main reasons of its wide application. In healthcare, glycerin is used as health supplement due to its ability to regulate body temperature by lowering core body temperature to delay dehydration process through increase in blood volume. In addition, at low temperatures, glycerin tend to supercool rather than crystallize. It is also capable of absorbing moisture from surrounding (hygroscopicity), and thus making it a suitable choice of coolant (Miner et.al., 2010).

Table 1 shows the properties of glycerin. An important point to state is that glycerin has a higher boiling point than water. Besides that, it has high viscosity and remains in 100\% liquid form at room temperature (Miner et.al., 2010). When concentrated glycerin supercools at low temperature, its viscosity will increase slowly and then rapidly until it become glassy about $89^{\circ} \mathrm{C}$. Due to its antifreeze properties, it is an excellent coolant for automobile radiator cooling systems. In addition, in some refrigeration systems, glycerin-water and glycerin-alcohol are used for quick-freezing foods. Glycerin also has high flash point $\left(350^{\circ} \mathrm{F}\right.$ or $177^{\circ} \mathrm{C}$ at $99 \%$ glycerol concentration) and fire point of $400^{\circ} \mathrm{F}\left(204^{\circ} \mathrm{C}\right.$ at $99.0 \%$ concentration). This means that the potential occurrence of fire hazard at ambient temperature, especially in tropical countries like Malaysia, is still low.

Table 1 - Properties of Glycerin (Miner et.al., 2010).

\begin{tabular}{ll}
\hline & Values Properties \\
\hline Molecular weight & 92.09 \\
Specific gravity (in air) & $1.2636\left(20^{\circ} \mathrm{c}\right) ; 1.2620\left(25^{\circ} \mathrm{c}\right)$ \\
Vapor Pressure & $0.0025 \mathrm{~mm}\left(50^{\circ} \mathrm{c}\right)$ \\
Boiling Point & $290^{\circ} \mathrm{c}(760 \mathrm{~mm})$ \\
& $152.0^{\circ} \mathrm{c}(5 \mathrm{~mm})$ \\
& $166.1^{\circ} \mathrm{c}(10 \mathrm{~mm})$ \\
Boiling Point at Low & $181.3^{\circ} \mathrm{c}(20 \mathrm{~mm})$ \\
pressure: & $190.9^{\circ} \mathrm{c}(30 \mathrm{~mm})$ \\
& $198.0^{\circ} \mathrm{c}(40 \mathrm{~mm})$ \\
& $18.17^{\circ} \mathrm{c}$ \\
\hline
\end{tabular}


Eny Nor Syahira Mohamad Hashim et al., International Journal of Sustainable Construction Engineering and Technology Vol. 11 No. 2 (2020) p. 101-108

\begin{tabular}{ll}
\hline Freezing Point (eutectic) & $(66.7 \%$ glycerol solution $)-$ \\
& $46.5^{\circ} \mathrm{c}$ \\
Viscosity & 1499 centipoises $\left(20^{\circ} \mathrm{c}\right)$ \\
Specific Heat & $0.5795 \mathrm{cal}$ pr gm deg $\left(26^{\circ} \mathrm{c}\right)$ \\
\hline
\end{tabular}

Water is widely available and its temperature is much closer to room temperature. Problems have been reported in Thermally Activated Building Systems (TABS) using water, but it is more associated with the inertia due to narrow cooling pipes rather than the coolant itself. In this research, this problem was not anticipated since tubes had been used rather than pipes (Lim. et.al., 2014). The idea came from the fact that water is used to remove hydration heat from concrete blocks during construction since it has high specific heat capacity (Lim. et.al., 2014). This means that water can absorb heat effectively. Furthermore, it has low viscosity and reasonably low boiling point to be used as coolant.

In this research, coolant tubes were used to achieve thermal comfort for the house models. The coolant tube was inspired by the passive pipe system embedded within a panel. Depending on the building's function, a passive pipe system may come in various forms and sizes. The coolant tubes were arranged in vertical loops as shown in Fig. 1.

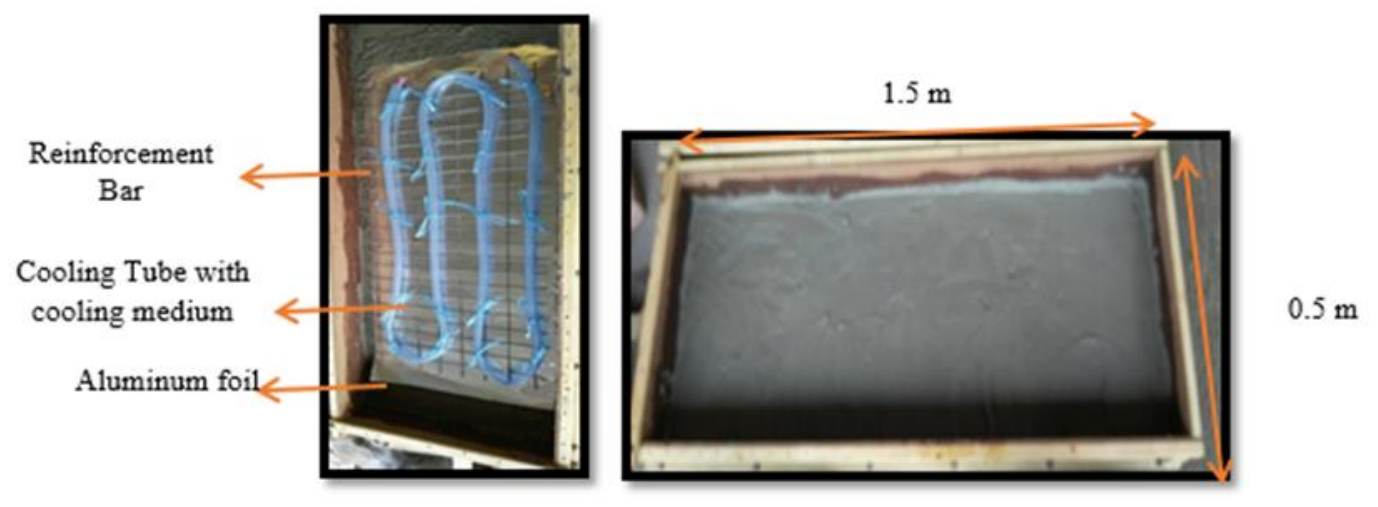

Fig. 1 - General arrangement of the cooling panel and dimension of the Precast Lightweight Foam Concrete

\subsection{Brick House Models}

Panel (PLFP)

All material for the house models were weighed and prepared in the laboratory. For the PLFP, a concrete mix design with target density of $1400 \mathrm{~kg} / \mathrm{m}^{3}$ and compression strength of 3.0 to $3.5 \mathrm{MPa}$ was prepared using sand, Ordinary Portland Cement (OPC), water and micro-bubbles. The materials used are shown in Fig. 2. Test cubes measuring 100mm x 100mm x 100mm were formed and marked to conduct compression test based on BS EN 12390-2:2009 (2009) after 7, 14 and 28 days of curing period. The target compression strength is similar to bricks.

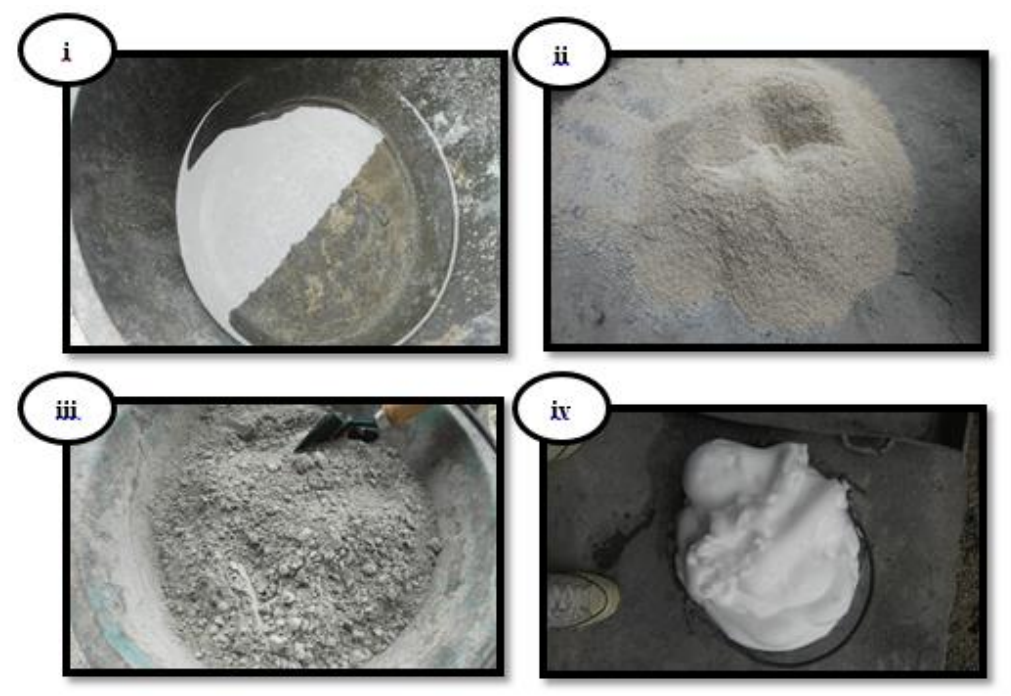

Fig. 2 - Materials of foam concrete; (i) sand, (ii) Ordinary Portland Cement (OPC), (iii) water and (iv) micro bubbles foaming 
All the precast PLFPs had a standardized size of $1.5 \mathrm{~m}$ x $0.5 \mathrm{~m} \mathrm{x} 0.1 \mathrm{~m}$. The thickness of the cooling panel used was $100 \mathrm{~mm}$, selected based on Table 3.1 of the Malaysian Standard, MS 1064: PART 10: 2001; this is the preferred size for reinforced concrete walls. The cooling system consisted of the cooling tubes, aluminum foils as insulation layer, and $6 \mathrm{~mm}$ reinforcement bars spaced at $100 \mathrm{~mm}$ intervals. Fig. 1 shows the general arrangement of the cooling panel and the dimension of the PLFP.

After that, two brick house models were built to test the effectiveness of the cooling system. The first was an ordinary brick house, serving as a control specimen and representing the most common houses in Malaysia. The second was the same brick house, but embedded with two PLFPs and cooling system. Both houses measured $2.0 \mathrm{~m} \times 2.0 \mathrm{~m} \times$ $2.0 \mathrm{~m}$ and are as shown in Fig. 3 and 4. Full scale prototype houses were not required since the objective was only to determine the effectiveness of the cooling system.
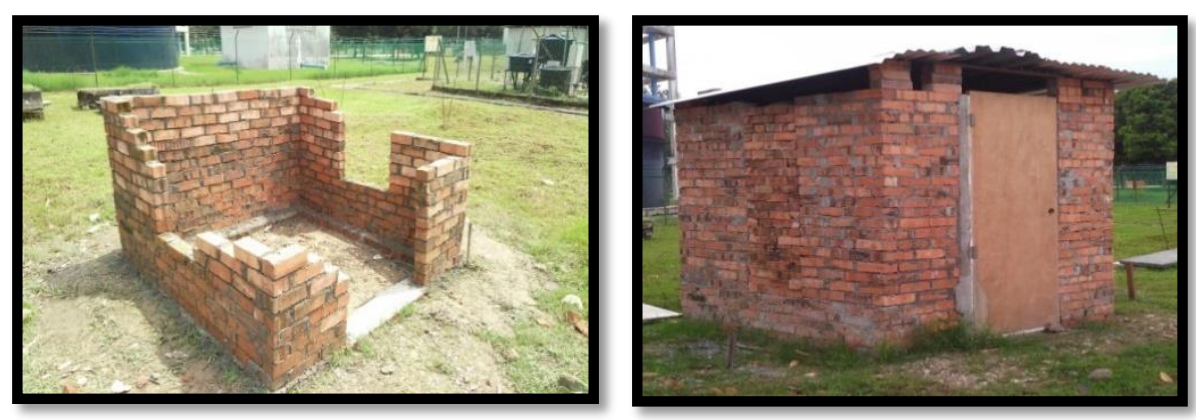

Fig. 3 - Construction of brick house model

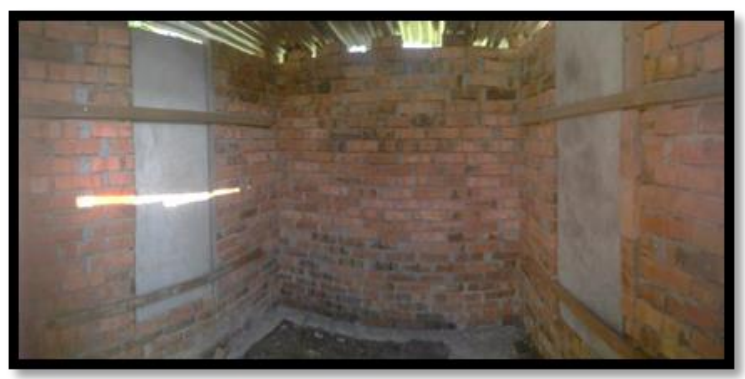

Fig. 4 - Location of the PLFPs with cooling system within the brick house model

The two important data measured in this study were humidity and temperature. Measurement was done using a 4 in 1 meter kit device as shown in Fig. 5 to record the minimum and maximum readings. This device is capable of measuring humidity, temperature, air velocity and also heat flux.

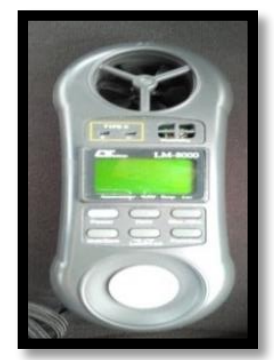

Fig. 5 - 4 in 1 meter kit for data measurement

The indoor temperature, outdoor temperature and humidity of the two house models were recorded at specific times of the day. The first was at 7:00 a.m. (sunrise), second was at 12:00 p.m. (mid-day), 4:00 p.m. (afternoon) and finally at 7:00 p.m. (sunset). Measurement was done for three consecutive days for each house model and cooling system. 
Eny Nor Syahira Mohamad Hashim et al., International Journal of Sustainable Construction Engineering and Technology Vol. 11 No. 2 (2020) p. 101-108

\section{Results and Discussions}

The concrete cube testing for compressive test was based on BS EN 12390-2:2009. Table 2 shows the compressive strength of the PLFP concrete cubes.

Table 2 - Compressive strength of the PLFP concrete cubes

\begin{tabular}{ccc}
$\begin{array}{c}\text { Time } \\
(\text { days })\end{array}$ & $\begin{array}{c}\text { Density } \\
\left(\mathbf{k g} / \mathbf{m}^{\mathbf{3}}\right)\end{array}$ & $\begin{array}{c}\text { Compressive strength } \\
(\mathbf{M P a})\end{array}$ \\
\hline 7 & 1280 & 1.8 \\
14 & 1300 & 3.0 \\
28 & 1300 & 3.4 \\
\hline
\end{tabular}

The highest temperature and relative humidity of control brick house model are shown in Table 3. Table 4 reports the data for brick house model with water cooling system while Table 5 reports the same for brick house with fine glycerin cooling system.

Table 3 - Temperature and relative humidity of control brick house model

\begin{tabular}{cccccccc}
\hline \multicolumn{2}{c}{ Time } & \multicolumn{2}{c}{$\begin{array}{c}\text { Temperature } \\
\left({ }^{\circ} \mathbf{C}\right)\end{array}$} & $\begin{array}{c}\text { Difference } \\
\left({ }^{\circ} \mathbf{C}\right)\end{array}$ & \multicolumn{2}{c}{$\begin{array}{c}\text { Humidity } \\
(\%)\end{array}$} & $\begin{array}{c}\text { Difference } \\
(\%)\end{array}$ \\
\hline Day & 12.00 & Out & 33.0 & & Out & 69.9 & \\
1 & p.m. & In & 31.5 & -1.5 & In & 70.9 & 1.0 \\
Day & 12.00 & Out & 33.7 & & Out & 68.5 & \\
2 & p.m. & In & 32.4 & -1.3 & In & 69.3 & 0.8 \\
Day & 12.00 & Out & 33.0 & & Out & 72.6 & \\
3 & p.m. & In & 31.8 & -1.2 & In & 71.68 & 0.9
\end{tabular}

Notation: Out $=$ outdoor temperature, $\mathrm{In}=$ indoor temperature, difference $\left({ }^{\circ} \mathrm{C}\right)=$ temperature differences $=$ in - out, differences $(\%)$; relative humidity differences $=$ In - Out

Table 4 - Temperature and relative humidity of water medium cooling house

\begin{tabular}{|c|c|c|c|c|c|c|c|}
\hline \multicolumn{2}{|c|}{ Time } & \multicolumn{2}{|c|}{$\begin{array}{c}\text { Temperature } \\
\left({ }^{\circ} \mathbf{C}\right)\end{array}$} & $\begin{array}{l}\text { Difference } \\
\quad\left({ }^{\circ} \mathrm{C}\right)\end{array}$ & \multicolumn{2}{|c|}{$\begin{array}{c}\text { Humidity } \\
(\%)\end{array}$} & $\begin{array}{c}\text { Difference } \\
(\%)\end{array}$ \\
\hline Day & 4.00 & Out & 32.3 & & Out & 69.9 & \\
\hline 1 & p.m. & In & 31.0 & -1.3 & In & 70.9 & 3.2 \\
\hline Day & 7.00 & Out & 28.9 & & Out & 68.5 & \\
\hline 2 & a.m. & In & 27.5 & -1.4 & In & 69.3 & 0.2 \\
\hline Day & 4.00 & Out & 34.5 & & Out & 72.6 & \\
\hline 3 & p.m. & In & 33.0 & -1.5 & In & 71.68 & 1.4 \\
\hline
\end{tabular}

Notation: Out $=$ outdoor temperature, In = indoor temperature, difference $\left({ }^{\circ} \mathrm{C}\right)=$ temperature differences $=$ in - out, differences $(\%)$; relative humidity differences $=$ In - Out

Table 5 - Temperature and relative humidity of fine glycerin medium cooling house

\begin{tabular}{cccccccc}
\hline \multicolumn{1}{c}{ Time } & \multicolumn{2}{c}{$\begin{array}{c}\text { Temperature } \\
\left({ }^{\circ} \mathbf{C}\right)\end{array}$} & $\begin{array}{c}\text { Difference } \\
\left({ }^{\circ} \mathbf{C}\right)\end{array}$ & \multicolumn{2}{c}{$\begin{array}{c}\text { Humidity } \\
(\%)\end{array}$} & $\begin{array}{c}\text { Difference } \\
(\%)\end{array}$ \\
\hline Day & 4.00 & Out & 36.0 & & Out & 57.5 & \\
1 & p.m. & In & 33.6. & -2.4 & In & 62.4 & 4.9 \\
& & & & & & & \\
Day & 12.00 & Out & 41.8 & & Out & 48.5 & \\
2 & p.m. & In & 38.3 & -3.5 & In & 57.9 & 9.4 \\
Day & 12.00 & Out & 37.5 & & Out & 54.7 & \\
3 & p.m. & In & 32.0 & -5.5 & In & 70.28 & 15.6 \\
\hline
\end{tabular}

Notation: Out $=$ outdoor temperature, $\mathrm{In}=$ indoor temperature, difference $\left({ }^{\circ} \mathrm{C}\right)=$ temperature differences $=$ in - out, differences $(\%)$; relative humidity differences $=$ In - Out 
Fig. 6 depicts the variation in highest temperature according to the reported data in Table 4 to 5 . Based on the reported data, the highest temperature difference between indoor and outdoor was $5.5^{\circ} \mathrm{C}$, at the brick house with glycerin cooling system at 12:00p.m of the third day. Compared to other house models, the temperature difference was consistently higher for the glycerin cooling system during the entire test period and at same time. This is a positive outcome since 12:00p.m is mostly the hottest time of the day. As such, it is the most crucial time to achieve thermal comfort. The graph also showed that water coolant had generally performed more consistently and better than the control brick house model, but its performance during the hottest time at 12:00 p.m was not significantly different from the control specimen. This could be attributed to glycerin's ability to supercool as compared to water, which would more or less maintain its temperature with its surrounding.

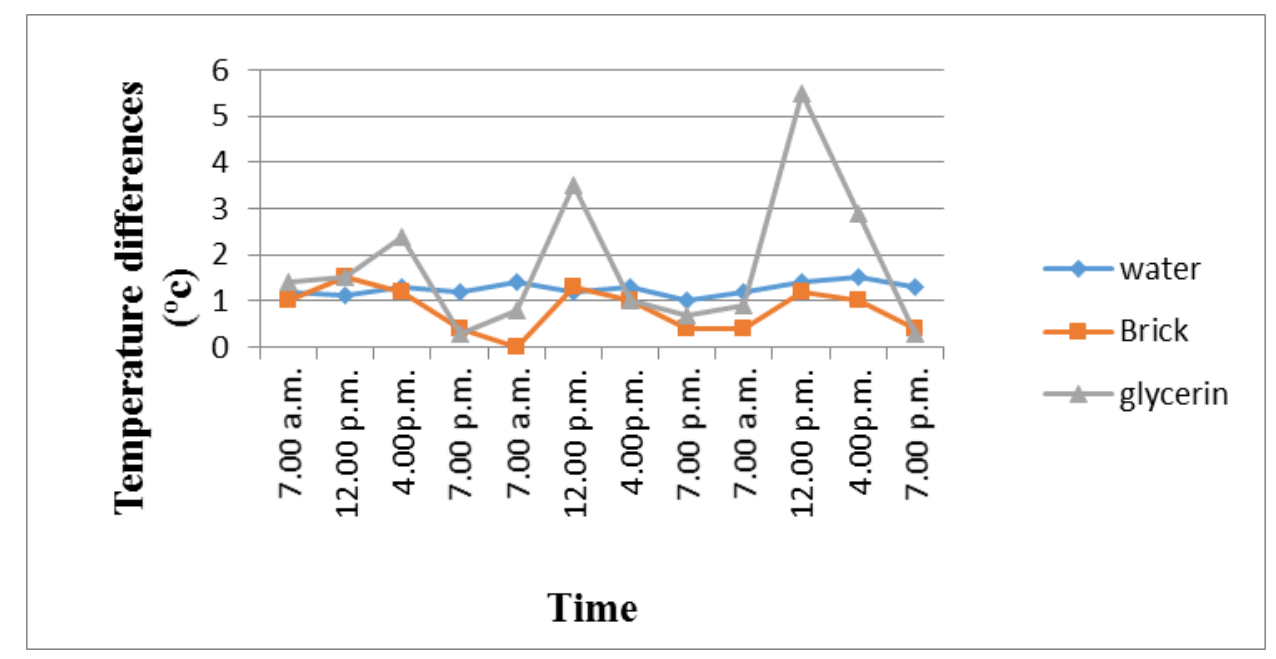

Fig. 6 - Indoor and outdoor temperature difference for the brick house models

Fig. 7 depicts the relative humidity of all house models. Similar to Fig. 6, the highest difference was again recorded for the brick house with glycerin cooling system, which was at $15.6 \%$. Besides that, the highest temperature difference for control brick house model was $9.7 \%$ and brick house with water cooling system was $6.0 \%$. The relative humidity measures the amount of water vapour present in air as compared to amount needed to reach saturation. The inconsistency in the reported relative humidity in this study could have been attribute to the model houses' ability to retain water vapor indoor. As mentioned before, glycerin is able to absorb moisture from its surrounding, this could be the main reason behind the comparatively higher relative humidity. Also, the weather condition could have also played a significant role in affecting the relative humidity.

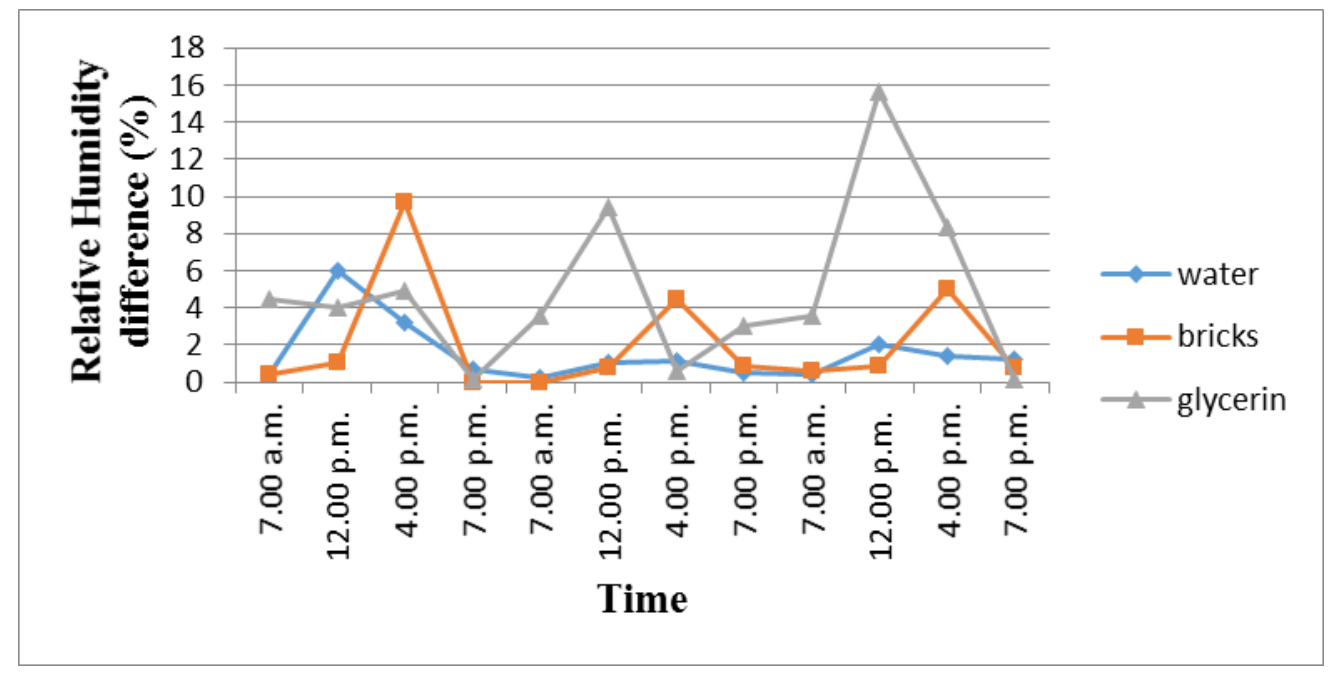

Fig. 7 - Relative humidity of the brick house models 


\section{Conclusion}

In conclusion, this research has demonstrated the effectiveness of incorporating a cooling system into a prototype building at a tropical climate. The indoor and outdoor temperature difference as well as relative humidity of three model houses had been studied and reported. The brick model house with a cooling system comprising cooling tubes with glycerin had given the best performance, making it a potential TABS to be adopted by the construction industry to achieve thermal comfort for modern buildings, especially in tropical countries.

\section{Recommendation}

To further improve the accuracy and reliability of the research outcome, it is recommended that the air velocity and weather condition during data collection are also taken into consideration. This will provide valuable insight into the interpretation of temperature difference as well as relative humidity. Other types of coolant should also be considered, such as nitrogen liquid since it also has rapid cooling effects or paraffin due to its high boiling points. The cooling tubes could also be replaced with other material, such as paraffin powder in capsule form. In this research, only a single brick house was built and modified based on testing condition. It is recommended to build at least two houses, one should be permanently the control brick house model. This is to ensure that comparisons can be made instantly and with more confidence, since the weather and atmospheric conditions would be identical. The arrangement of cooling tubes could also play a role in affecting the results, this should be studied to justify the claim. Lastly, the test period should be increased to improve the reliability and stability of the cooling system's performance. This is important since the solution, once adopted by the industry, will be a long-term solution for most buildings

\section{Acknowledgement}

Authors would like to thank you to Universiti Tun Hussein Onn Malaysia.

\section{References}

British Standard (2009), Testing hardened concrete. Making and curing specimens for strength tests, London: BS EN 12390-2:2009

Department of Standards Malaysia (2009). Guide to modular coordinationin buildings:Part 10: coordinating sizes andpreferred sizes for reinforcedconcrete components. Putrajaya : MS 1064:PART 10:2001

Engineering ToolBox, (2009). Boiling Point of Water and Altitude. [online] Retrieved on 20 April 2019 from https://www.engineeringtoolbox.com/boiling-points-water-altitude-d_1344.html

Halipah, I. S. (2015). Reinventing Traditional Malay House for Sustainable Housing Design : Obstacle and Solution Jurnal Teknologi Full paper Reinventing Traditional Malay House for Sustainable Housing Design: Obstacle and Proposed Solution,

Lim, J. H., Song, J. H., \& Song, S. Y. (2014). Development of operational guidelines for thermally activated building system according to heating and cooling load characteristics. Applied Energy, 126, 123-135.

Malaysian Meteorological Department. (2009). Climate Change Scenarios for Malaysia 2001 - 2099. Zhurnal Eksperimental'noi I Teoreticheskoi Fiziki, 1-84

Mbamalu (2013). Glycerin and the market, Masters Theses and Doctoral Dissertations. University of Tennessee at Chattanooga pp (115)

Miner, C., \& Dalton NN. (2010). Glycerine: An Overview. Chem Soc Monogr. 1953, 117(212), 1-27

Mohamad, Noridah (2010). The structural behaviour of precast lightweight foamed concrete sandwich panel as a load bearing wall. $\mathrm{PhD}$ thesis, Universiti Teknologi Malaysia

Myhren, J. A., \& Holmberg, S. (2008). Flow patterns and thermal comfort in a room with panel, floor and wall heating. Energy and Buildings, 40(4), 524-536 
Eny Nor Syahira Mohamad Hashim et al., International Journal of Sustainable Construction Engineering and Technology Vol. 11 No. 2 (2020) p. 101-108

Prakash, D., \& Ravikumar, P. (2015). Analysis of thermal comfort and indoor air flow characteristics for a residential building room under generalized window opening position at the adjacent walls. International Journal of Sustainable Built Environment, 4(1), 42-57 